\title{
Geospatial Opinion on Unusual Locust Swarm Invasions during Amphan Cyclone
}

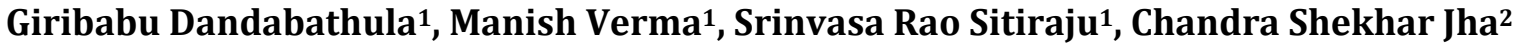 \\ ${ }^{1}$ Regional Remote Sensing Centre-West, NRSC, Indian Space Research Organization, Jodhpur, India \\ ${ }^{2}$ National Remote Sensing Centre, Indian Space Research Organization, Hyderabad, India \\ Email:dgb.isro@gmail.com,verma_mk@nrsc.gov.in,ssrao@nrsc.gov.in,jha_cs@nrsc.gov.in
}

How to cite this paper: Dandabathula, G., Verma, M., Sitiraju, S. R., \& Jha, C. S. (2020). Geospatial Opinion on Unusual Locust Swarm Invasions during Amphan Cyclone. Journal of Geoscience and Environment Protection, 8, 144-161.

https://doi.org/10.4236/gep.2020.812009

Received: November 20, 2020

Accepted: December 19, 2020

Published: December 22, 2020

Copyright (c) 2020 by author(s) and Scientific Research Publishing Inc. This work is licensed under the Creative Commons Attribution International License (CC BY 4.0)

http://creativecommons.org/licenses/by/4.0/

\section{Open Access}

\begin{abstract}
The desert locust, Schistocerca gregaria Forsk. (Orthoptera: Acrididae) is a peculiar insect that exhibits density-dependent phase polyphenism. Gregarious phase enables desert locust to form a large groups and mass migrations during which significant crop loss and food security issues may occur. Currently, the most recent upsurge of desert locust is prevailing across Eastern Africa and Southwestern Asia. Usually desert locusts are restricted to regions like semi-arid and arid regions. A super cyclonic storm, namely Amphan originated during May 2020, in the Bay of Bengal of North Indian Ocean has influenced numerous swarms to migrate from the Thar desert region to other parts of India. In this research, satellite data were used to investigate the reasons for this sudden swarm migration. The results that revealed the wind jets passing above the Thar desert region have integrated with the cyclogenesis of Amphan and led to the formation of conduits. The favorable conditions in the conduits include the open sky conditions, air temperature and fresh vegetation availability. Moreover, the wind settings in the conduits have enabled the swarm migrate to follow the downwind facing the sunrays during early mornings for an easy and successful take-off. It is observed that during the take-off session the wind speed at $850 \mathrm{hPa}$ pressure level is mostly double than that of surface wind in both the conduits.
\end{abstract}

\section{Keywords}

Cyclone-Borne Winds, Locust Swarms, Migration, Amphan, Desert Locust, Trajectory

\section{Introduction}

The desert locust, Schistocerca gregaria Forsk, (Orthoptera: Acrididae), is a typ- 
ical African species considered as the most notorious insects in the world and has the largest geographical distribution spreading over 30 countries (Wilps, 1997; Song, 2004). The peculiarity of Schistocerca gregaria is that it exhibits phenotypic plasticity called density-dependent phase polyphenism in which local population density affects the expression of a variety of behavioral, physiological, biochemical, molecular, reproductive, and morphological traits (Cabej, 2019). While in solitarious phase desert locust is coloured, shy and avoids one another. Gregarious phase starts with an increased density of surrounding conspecific population thereby forming large groups and mass migrations, travelling as marching band of flightless juveniles or vast flying swarms of winged adults (Simpson \& Sword, 2009; Cabej, 2019). A single locust swarm can contain billions of insects (Cressman, 2013; Topaz et al., 2012).

A life span of a Desert locust comprises of egg-development stage, hopper or nymph, and the winged adults; all these stages are highly influenced by weather and ecological conditions impacting their life span (Cressman \& Stefanski, 2016). Surface and root-zone soil moisture, soil type, air temperature, land surface temperature, and local ecological conditions will influence the breeding process as well as egg development process (Pedgley, 1980; Symmons \& Cressman, 2001). The new-born nymph moults five to six times in its lifespan depending on the environmental conditions like occasional rains, air temperature, early morning and later afternoon temperature settings, and the wind (Cressman \& Stefanski, 2016). Towards completing various instar stages, its body becomes young adult known as fledgling that has fresh wings gearing to fly and ability to reproduce (Gomez et al., 2018). Complete flying capabilities will be acquired during the immature adult stage. Maturation and thereafter stages in the adult phase, depend on various environmental conditions like rainfall, land surface temperature, air temperature, vegetation status, and wind parameters (Steedman, 1988).

The phenomenon of gregarization occurs rapidly due to the aggregation just after a few hours of forced crowding. During this crowding, there is increased attraction between the members because of serotonin release at the thoracic ganglia, a part of the central nervous system that gets triggered while mechano-sensory stimulation of a hind femur (Anstey et al., 2009). During the process of migration, parameters like density of gregariousness, early morning sun conditions, wind speed, wind direction, and local topography of the landscape play a vital role on the swarm trajectory (Kennedy, 1951). Evidences of long-range swarm displacements do exist; like a non-stop flight of trans-Atlantic from West Africa to the Caribbean during October 1988 that has covered a distance of about 5000 km (Richardson \& Nemeth, 1991). Researchers have attributed this long-range swarm displacement to the winds originated due to the long lived Hurricane Joan (10 ${ }^{\text {th }}$ Oct.- $2^{\text {nd }}$ Nov. 1988) (Richardson \& Nemeth, 1991; Lorenz, 2009).

In general, the habitat distribution of Desert locust extends from West Africa through the Middle East to South-West Asia (Wilps, 1997; Song, 2004). Maps shown in Figure 1(a) and Figure 1(b) represent the habitat locations of desert 


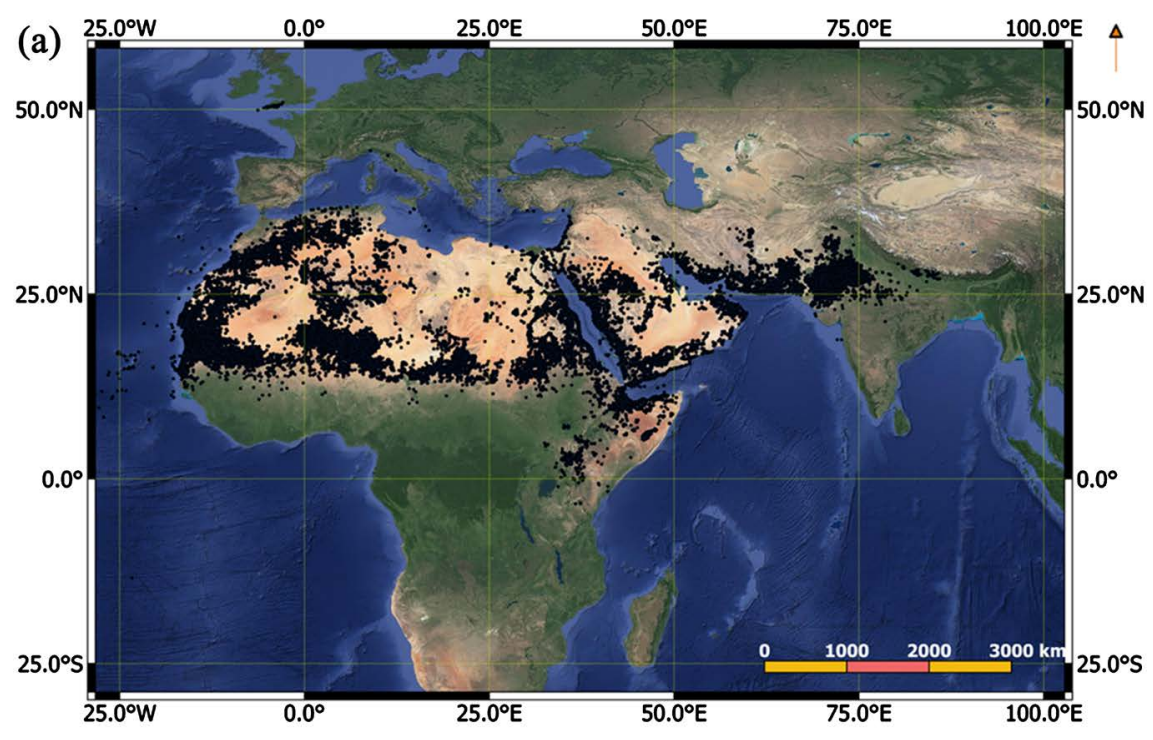

- Reported locations of hopper or adult (1995-2020)

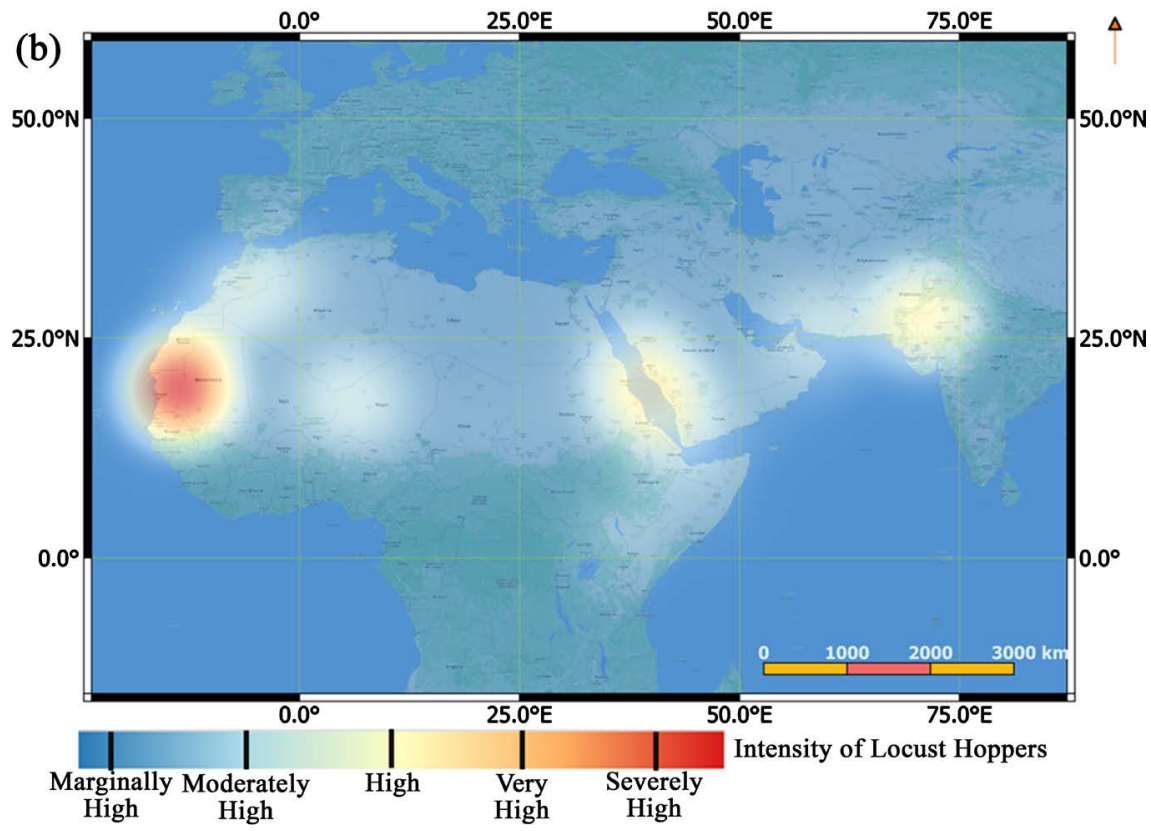

Figure 1. Habitat and Heat-map of desert locust. (a) Locations of hoppers and adults of desert locust (1985 to mid-2020) (Data source-FAO's Locust Hub web portal). (b) Heatmap generated using Kernel density estimation algorithm over the point data representing the intensity of Hoppers sightings from 1985 to mid-2020.

locust and corresponding heat-map respectively. Certain parts in the countries like the Islamic Republic of Iran, Pakistan, and India are most vulnerable to desert locust in the South-west Asia. In India, Desert locust population is normally present during the summer period in the Thar desert region of western Rajasthan and to a lesser extent in Gujarat state (Uvarov, 1934; Ramchandra Rao, 1942).

Agriculture and allied sectors are the largest sources of livelihoods in India, and the threat of locust looms to food security and impacts agriculture produc- 
tivity. Studies related to desert locust are highly rational for agriculture dependent countries like India (Ramchandra Rao, 1942).

A Super Cyclonic Storm (SCS) namely Amphan has originated from the remnant of a low pressure area in the near equatorial easterly wave over south Andaman Sea and adjoining South-eastern Bay of Bengal, has lived from $16^{\text {th }}$ to $21^{\text {st }}$ May 2020 (IMD, 2020). During the living and decay periods of the cyclone, there have been widespread news articles reported unprecedented sightings of locust swarms in the south central parts and Indo-Gangetic plane of India (Outlook, 2020; The Hindu, 2020). Numerous set of swarm have migrated from the Thar desert region to other parts of India through two separate conduits; first one during the living period and the second one during the decay phase of Amphan cyclone.

The objectives of this research include usage of geospatial data to investigate the ecological conditions that favored the swarm migration through these two conduits and verify the reasons for widespread migration of desert locusts to non-invasive zones during these cyclone episodes.

\section{Materials and Methods}

\subsection{Desert Locust Swarm Data}

Food and Agriculture Organization (FAO) maintains Desert Locust Information Service (DLIS) in which the data from regional centres and meteorological offices of various countries that were affected by locust will be ingested and the services like early warning information systems can be realized (Cressman, 1997).

The Locust Hub portal provides access to location based data related to Hoppers, Bands, Adults, Swarms, ecological conditions, and details of control operations taken up in various countries (Locust Hub, 2020). The swarms' dataset contains attributes like date-time stamp, geolocation information, location name, and area affected. Locust attack events reported in the news media were considered for analyzing the transit paths used by the swarms.

For this study, sub-set of data pertaining to the swarms that oscillated in Indian sub-continent during the pre, living, and post Amphan cyclonic events have been retrieved from the Locust Hub portal. Table 1 shows the number of swarms oscillated during various time periods of Amphan cyclone. Figure 2(a)

Table 1. Details of swarm sightings at various time periods along Indo-Pak border and the scheduled Thar desert region of India.

\begin{tabular}{ccc}
\hline Region of locust oscillations & Time Period & $\begin{array}{c}\text { No. of locust } \\
\text { swarms reported }\end{array}$ \\
\hline $\begin{array}{c}\text { Indo-Pak border and the scheduled Thar desert region } \\
\text { Scheduled Thar desert region in India }\end{array}$ & 1 Jan to 09 May, 2020 & 2192 \\
Swarms transited through the first conduit & 16 May to 21 May, 2020 & 36 \\
$\begin{array}{c}\text { Entry of fresh swarms into the Thar desert region } \\
\text { from Pakistan during the living period of Amphan }\end{array}$ & 16 May to 21 May, 2020 & 22 \\
Swarms transited through the second conduit & 22 May, to 28 May, 2020 & 49 \\
\hline
\end{tabular}




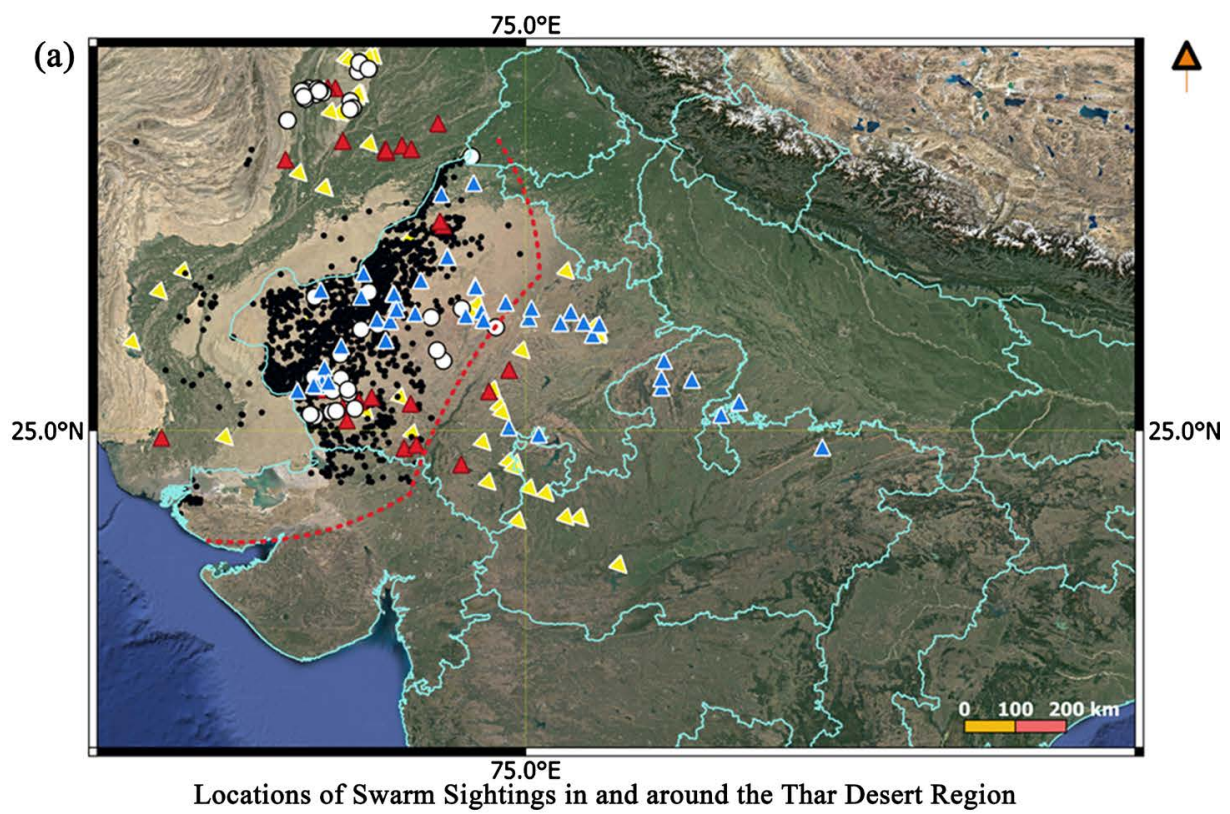

- 2018-10 May, 2020 O11-15 May, $2020 \triangle 16-18$ May, $2020 \triangle 19-21$ May, $2020 \triangle 22-28$ May, 2020

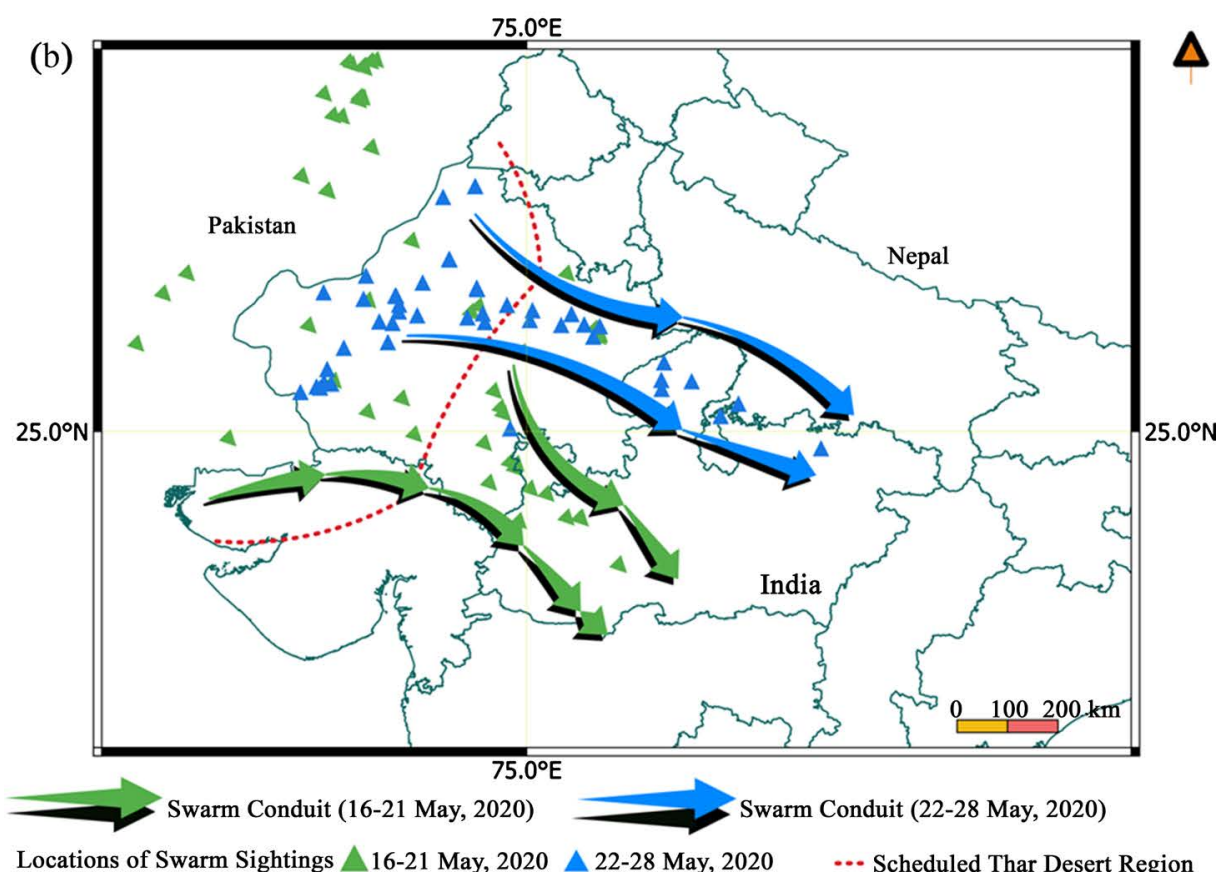

Figure 2. (a) Map showing locations of Locust swarms in and around the Thar Desert during various phases of Amphan cyclone. In this map, archival sightings of the Desert locust till the period of Amphan Cyclone are shown in black dots. Note the movement of swarms towards the Southeast direction during the living period of the Amphan cyclone and towards the Eastern side after the cyclonic episode. (b) Map showing the swarm conduits formed during the living period of Amphan cyclone (green colour conduit) and post cyclonic episode (blue colour conduit). The first conduit favoured the migration of swarms to the south central parts of India and second conduit favoured migration of swarms to the Indo-Gangetic plane.

shows the location of swarms oscillated during various dates that are related to the interest of this research. Figure 2(b) shows the extents of the conduits that 
were preferred by the swarms to migrate during various phases of Amphan cyclones.

\subsection{Study Area}

Environmental and ecological conditions in the Indo-Pak border region and at parts of the Thar Desert region are highly conducive for the Desert locust (Uvarov, 1934; Ramchandra Rao, 1942). These areas act as a front-line for Desert locust and have been the primary reasons for the major locust plagues happened during the last 150 years in India (LWO, 2020).

Cyclones like Sagar, Mekunu and Luban brought heavy rains to the Empty Quarter on the Arabian Peninsula and have favored the ecological conditions to exacerbate the desert locust outbreaks along the Red Sea coast during the winters of 2018/2019 (Locust Watch, 2020). As a result, three generations of breeding occurred that was undetected and not controlled. Swarms have started invading from the Empty Quarter by January 2019, and by June 2019 they have invaded other countries like Yemen, Saudi Arabia, Iran, Pakistan and India. The situation has been alerted by the Food and Agriculture Organization of the United Nations (FAO) and declared Locust-Upsurge 2019-2020 (Locust Watch, 2020). Migration of spring-bred swarms from southwest Pakistan to the scheduled desert region of Rajasthan, India occurred by the third-week of April, 2020 and as a result numerous invasions by the adults groups and swarms were reported across the scheduled desert region of India during the start of May, 2020 (Locust Bulletin, 2020).

By virtue of Amphan Cyclone, two conduits at two different times and regions (as indicated in Figure 2(b)) were formed that favored the migration of swarms from the scheduled desert region to non-invasive parts of the country; the first conduit favored the migration of swarms from the scheduled desert region to the south central part of India during $16^{\text {th }}$ to $21^{\text {st }}$ May, 2020 and the second conduit favored the swarm migration towards the Indo-Gangetic plan during $22^{\text {nd }}$ to $28^{\text {th }}$ May, 2020. In this study, emphasis has been given to study the details of these two conduits in terms of vegetation, basking conditions and wind dynamics. The extent of the first conduits lies within the coordinates of $27.00^{\circ} \mathrm{N}, 74.00^{\circ} \mathrm{E}$ and $21.00^{\circ} \mathrm{N}, 77.00^{\circ} \mathrm{E}$. Similarly the second conduits lie within the extent of $29.00^{\circ} \mathrm{N}$, $74.00^{\circ} \mathrm{E}$ and $24.00^{\circ} \mathrm{N}, 81.00^{\circ} \mathrm{E}$.

\subsection{Amphan Cyclone Data and Early Morning Basking Conditions}

INSAT-3D/3DR series of the Indian National Satellites are current operational duo-meteorological satellite system that provides multi-spectral images of the Earth and the atmosphere at every 15-minute interval from the Imager sensor (Deb et al., 2020). In this study, data products from INSAT-3D/3DR have been used to map the cyclone track and early morning basking conditions during all the cyclonic episodes. 
The distance from the outer layer of the cyclone to the first conduit varied from $800 \mathrm{~km}$ to $1800 \mathrm{~km}$ during its traverse route that spread over a 6 days period, and due to this vast distance the cumulonimbus clouds originated due to Amphan never overshadowed the regions of the conduits. Figure 3(a) shows the INSAT-3D data acquired at $1200 \mathrm{Hrs}$. (IST) on $20^{\text {th }}$ May 2020 and overlaid with the track of cyclonic movement. From INSAT-3D \& 3DR data, it is observed
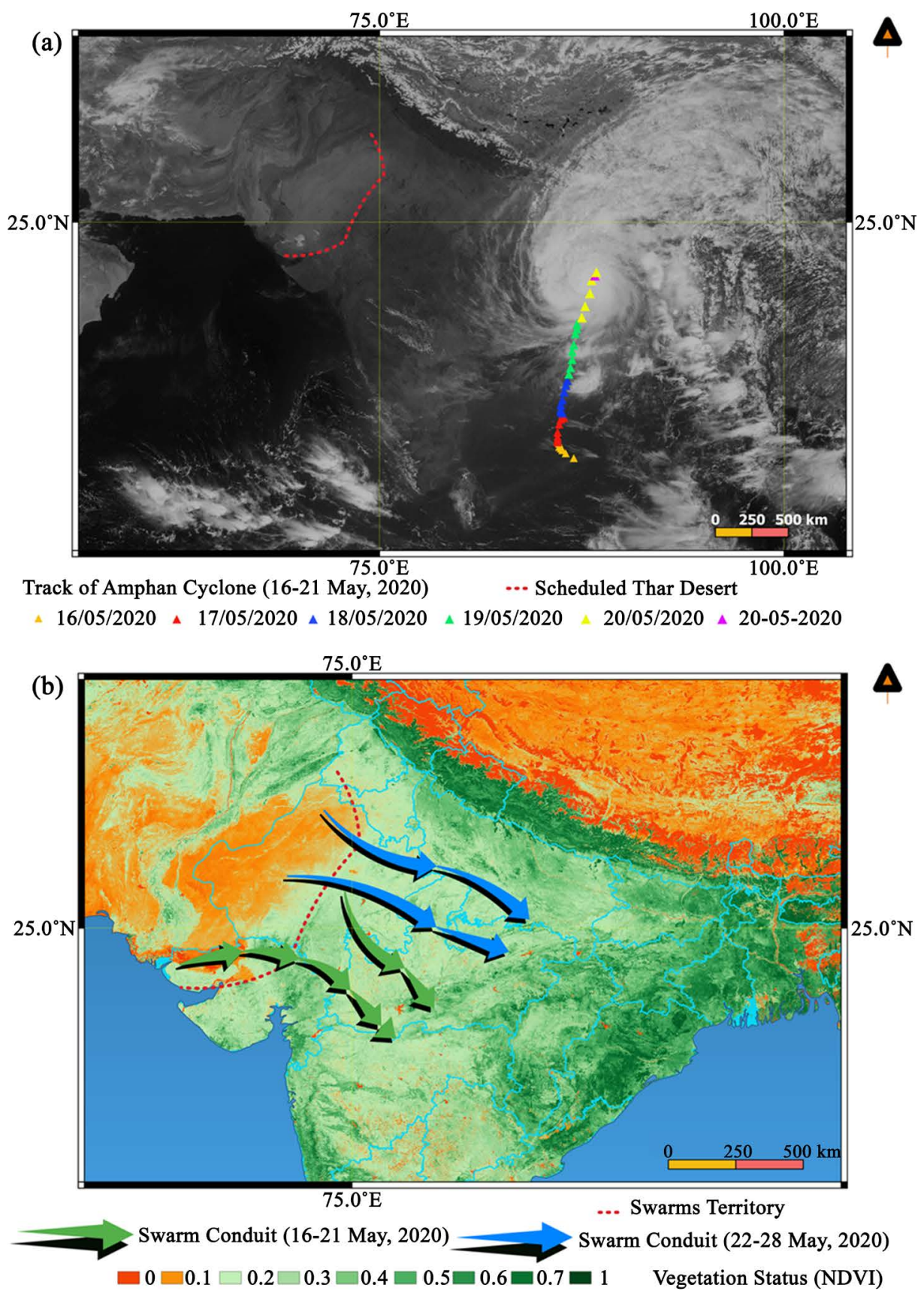

Figure 3. (a) Map showing satellite image acquired by INSAT-3D at 12 '00 Hrs. (Indian Standard Time) on $20^{\text {th }}$ May 2020. (b) Map showing vegetation status in Indian sub-continent during mid-May. The range of NDVI values in the extent of both the conduits varied from 0.2 to 0.3 . 
that until two hours from the sunrise, the sky conditions in both the conduits are mostly cloud free with minor presence of scattered cirrus or cirrostratus clouds during $16^{\text {th }}$ to $28^{\text {th }}$ May, 2020. Earlier researchers suggested that swarms will have warm-up session by basking in the Sun so that their muscles will get enough strength for successful take-off in the mid-morning sessions (Kennedy, 1951; Cressman \& Stefanski, 2016).

\subsection{Vegetation Status en Route Swarm Trajectories}

Vegetation status plays an important role while performing a forecast of the swarms' movement (Uvarov, 1934; Kennedy, 1951; Topaz et al., 2012). Normalized Difference Vegetation Index (NDVI) based on red and infrared bands of information from the space borne remote sensing sensors can be a robust metric for estimating photosynthetically active vegetation coverage and is a widely adopted vegetation index (Yang et al., 2017). NDVI values ranges from -1 to 1 ; with negative valued pixels representing non-vegetation and towards 1 tends to pixels with healthy vegetation.

In this study, vegetation status has been retrieved from EROS Moderate Resolution Imaging Spectroradiometer (eMODIS) data collection pertaining to midMay 2020. Figure 3(b) represents the vegetation status through NDVI over India sub-continents and surrounding regions during mid-May 2020. It is observed that in both the conduits the vegetation status is mostly ranging 0.2 to 0.3 indicating a fresh vegetation growth.

\subsection{Air Temperature and Wind Parameters}

A climate reanalysis gives a numerical description of the recent climate, produced by combining models with observations. The role of reanalysis in climate monitoring applications is gaining momentum and already finding major role in applications related to atmospheric sciences. The latest climate reanalysis products disseminated by the European Centre for Medium-Range Weather Forecasts (ECMWF) as an hourly data on many atmospheric, land-surface and sea-state parameters through the project namely ECMWF Reanalysis $5^{\text {th }}$ Generation (ERA5) (Hersbach et al., 2020). ERA5 data are available on regular latitude-longitude grids at $0.25^{\circ} \times 0.25^{\circ}$ resolution, with atmospheric parameters at 37 pressure levels and offers the best agreement and correlation with the real time data (Ramon et al., 2019). Wind settings at an approximate pressure level of $850 \mathrm{hPa}$ (nearly $1500 \mathrm{~m}$ from surface height that corresponds to the lowest troposphere level) are highly strategic for the swarm flight trajectories (Cressman \& Stefanski, 2016; Rosenberg \& Burtm, 1999; Makra et al., 2017; Wang et al., 2020). In this study, mean wind speed and mean wind direction at various cyclonic episodes in the both conduits were retrieved from the $\mathrm{u}$ and $\mathrm{v}$ components of ERA5 wind data at surface level and $850 \mathrm{hPa}$ level. Figure 4(a) shows the typical setting of wind speed and direction the period of Amphan Cyclone during which it has shown the characteristics of Very Severe Cyclonic Storm (VSCS) with 155 

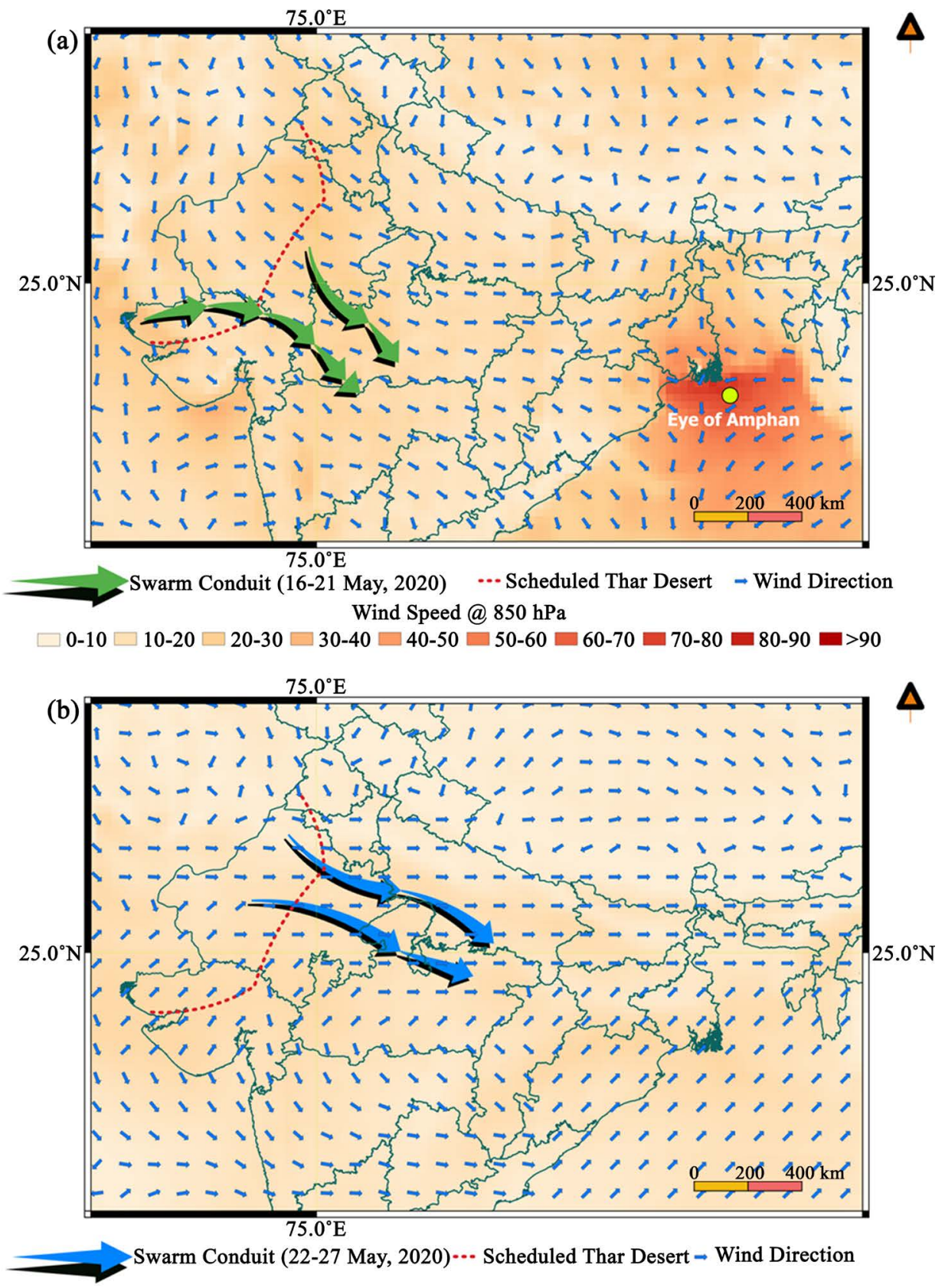

$\square 0-10 \square 10-20 \square 20-30 \square 30-40 \square 40-50 \square 50-60 \square 60-70 \quad$ Wind Speed @ 850 hPa

Figure 4. (a) Typical wind settings during the living period of Amphan cyclone. The peak of wind speed geared by Amphan cyclone which is nearing to landfall from the Bay of Bengal can be seen in the map. Note the wind direction in the conduit is oriented towards south-easterly direction. (b) Typical settings of wind speed and wind direction during cyclone decay phase.

- $165 \mathrm{kmph}$ winds gusting to $185 \mathrm{kmph}$. Similarly, Figure 4(b) shows the typical settings of wind speed and wind direction during the cyclone decay phase. Desert locusts are highly influenced by the air temperature; increase in air temperature increases the thoracic temperature, which in turn propels the swarm activity (Gunn et al., 1948).

Surface mean air temperature (above 2 meters) within the first two hours after 
sunrise has been computed from ERA5 data for both the conduits. The observations yielded $29.6^{\circ} \mathrm{C}$ (during 16-21 May 2020) and $31.2^{\circ} \mathrm{C}$ (during 22-28 May 2020 ) in the first and second conduits respectively.

Table 2 represents the values of mean wind settings (wind speed and direction) at the surface and $850 \mathrm{hPa}$ level in both the conduits that supported the swarm migration during the living period and post Amphan cyclone event.

\subsection{Methods}

Ingesting the locust swarms data (as shown in Figure 2(a)) pertaining to various

Table 2. Mean wind settings (at the surface and $850 \mathrm{hPa}$ pressure levels) in the conduits that supported the swarm migration during the living period and post Amphan cyclonic event at 0600 \& 0900 Hrs.

\begin{tabular}{|c|c|c|c|c|}
\hline \multirow{2}{*}{$\begin{array}{c}\text { Conduit } \\
\text { No. }\end{array}$} & \multirow{2}{*}{$\begin{array}{l}\text { Date of Observation } \\
\text { (dd/mm/yyyy) }\end{array}$} & \multirow{2}{*}{$\begin{array}{c}\text { Time of Observation } \\
\text { (Hrs.) (IST) }\end{array}$} & \multicolumn{2}{|c|}{ Mean wind direction $\&$ speed $(\mathrm{kmph})$} \\
\hline & & & Surface & $850 \mathrm{hPa}$ \\
\hline \multirow{12}{*}{1} & \multirow{2}{*}{$16-05-2020$} & 0600 & 1550@13 & 1600@29 \\
\hline & & 0900 & 1550@19 & 1600@19 \\
\hline & \multirow{2}{*}{$17-05-2020$} & 0600 & 1200@11 & 1300@36 \\
\hline & & 0900 & 1350@15 & 1450@27 \\
\hline & \multirow{2}{*}{$18-05-2020$} & 0600 & 1200@14 & 1500@24 \\
\hline & & 0900 & 1350@22 & 1450@42 \\
\hline & \multirow{2}{*}{$19-05-2020$} & 0600 & 1250@12 & 1700@24 \\
\hline & & 0900 & 1200@11 & 1600@21 \\
\hline & \multirow{2}{*}{ 20-05-2020 } & 0600 & 1200@14 & 1600@36 \\
\hline & & 0900 & 1350@14 & 1700@29 \\
\hline & \multirow{2}{*}{$21-05-2020$} & 0600 & 1000@10 & 1450@25 \\
\hline & & 0900 & 1050@19 & 1300@44 \\
\hline \multirow{14}{*}{2} & \multirow{2}{*}{$22-05-2020$} & 0600 & 1000@13 & 1100@50 \\
\hline & & 0900 & 1050@20 & 1150@43 \\
\hline & \multirow{2}{*}{$23-05-2020$} & 0600 & 1100@11 & 1150@50 \\
\hline & & 0900 & ‘1100@22 & 1100@47 \\
\hline & \multirow{2}{*}{$24-05-2020$} & 0600 & 900@11 & 1400@28 \\
\hline & & 0900 & 1000@22 & 1150@29 \\
\hline & \multirow{2}{*}{$25-05-2020$} & 0600 & 900@09 & 1400@28 \\
\hline & & 0900 & 1000@14 & 1150@46 \\
\hline & \multirow{2}{*}{$26-05-2020$} & 0600 & 900@17 & 950@48 \\
\hline & & 0900 & 1000@17 & 900@38 \\
\hline & \multirow{2}{*}{$27-05-2020$} & 0600 & 1550@15 & 1000@33 \\
\hline & & 0900 & 750@22 & 950@46 \\
\hline & \multirow{2}{*}{$28-05-2020$} & 0600 & 650@12 & 1000@54 \\
\hline & & 0900 & 700@20 & 700@51 \\
\hline
\end{tabular}


periods of Amphan cyclone into a Geo-analytics tool, namely Aggregate-Points has resulted in identifying two sets of boundaries (conduits) based on their point association and arrangement. These two sets of aggregated areas were shown as two conduits in Figure 2(b).

Data related to the daily cloud cover, air temperature after sunrise, and the vegetation status in the extents of both the conduits were retrieved using various image processing tools. Mean wind speed and mean wind direction (at the surface and at $850 \mathrm{hPa}$ levels) for both the conduits were computed from the series of temporal data (every three hours from sunrise to evening $1800 \mathrm{Hrs}$.) and their trend has been analysed.

All these data sets which are in the spatial format were used to derive the perspectives and the results from the trend analysis of the wind parameters are discussed in the subsequent section.

\section{Results}

Table 3 represents the summary of observations derived from spatial data components that includes information pertaining to cloud conditions, air temperature settings, vegetation status, and the wind parameters.

Figure 5(a) and Figure 5(b) shows the profiles of hourly mean wind speeds at surface and $850 \mathrm{hPa}$ pressure levels in the first and second conduits respectively. Trend analysis over the wind speed data pronounces that the wind speed at 850 $\mathrm{hPa}$ level is mostly double of the wind speed at surface level for all the days during the post basking period (considered at $0800 \mathrm{Hrs}$.) in both the conduits. Equation 1 represents the mathematical criteria that is holding true for all the days with respect to the wind speeds at surface and $850 \mathrm{hPa}$ pressure level at the post basking period in both the conduits (evident from the observation given in Table 2).

Table 3. Observations derived from the spatial data components in the swarm conduits.

\begin{tabular}{|c|c|c|}
\hline Data Set & Conduit \# 1 & Conduit \# 2 \\
\hline Dates of observations & $16^{\text {th }}$ to $21^{\text {st }}$ May 2020 & $22^{\text {nd }}$ to $28^{\text {th }}$ May 2020 \\
\hline Cloud conditions (at second hour after sunrise) & $\begin{array}{l}\text { Most of the days the sky is cloud free } \\
\text { with minor presence of cirrus cloud }\end{array}$ & $\begin{array}{l}\text { Most of the days the sky is cloud free with } \\
\text { minor presence of cirrostratus cloud }\end{array}$ \\
\hline Vegetation status & $\begin{array}{l}\text { Most of the area in the conduit } \\
\text { contains agriculture land favouring } \\
\text { fresh vegetation with sparse settlements }\end{array}$ & $\begin{array}{l}\text { Most of the area in the conduit contains } \\
\text { agriculture land favouring fresh } \\
\text { vegetation with sparse settlements }\end{array}$ \\
\hline Mean air temperature (approximately at two hours from sunrise) & $29.6^{\circ} \mathrm{C}$ & $31.2^{\circ} \mathrm{C}$ \\
\hline $\begin{array}{l}\text { Mean wind speed at surface (after two hours from sunrise) } \\
(\mathrm{kmph})\end{array}$ & 12 & 14 \\
\hline $\begin{array}{l}\text { Mean wind speed at } 850 \mathrm{hPa} \text { pressure level (after two hours } \\
\text { from sunrise) }(\mathrm{kmph})\end{array}$ & 30 & 41.5 \\
\hline Mean wind direction (day) @850 hPa pressure level & $\begin{array}{l}1250 \text { (winds oriented towards } \\
\text { Southeastern direction) }\end{array}$ & $\begin{array}{l}950 \text { (winds oriented towards Eastern } \\
\text { direction) }\end{array}$ \\
\hline $\begin{array}{l}\text { Mean ratio of Wind speed at Surface and } 850 \mathrm{hPa} \text { pressure } \\
\text { level (two hours from sunrise) }\end{array}$ & $\sim 1: 2.2$ & $\sim 1: 2.4$ \\
\hline
\end{tabular}



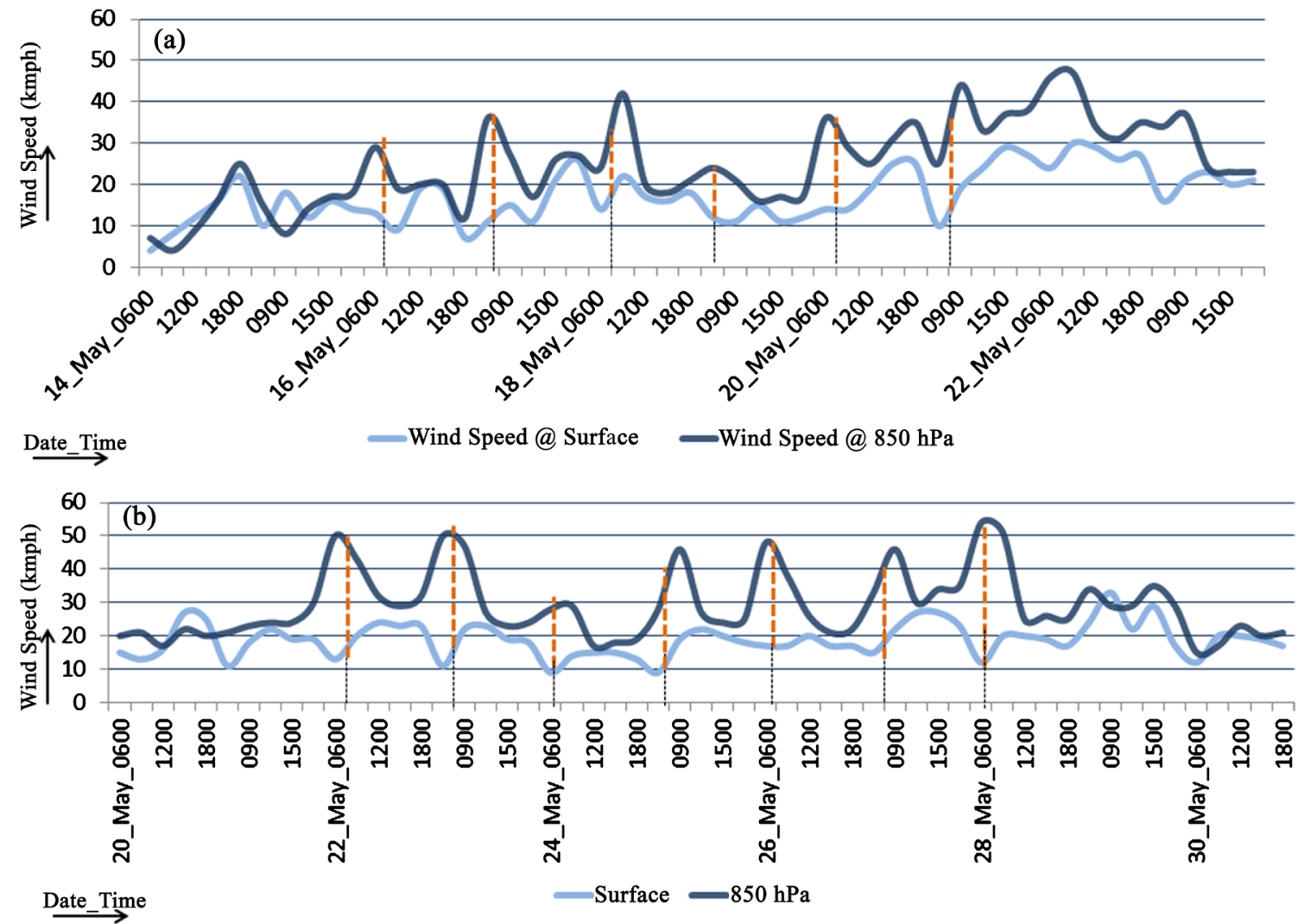

Figure 5. Profiles of mean wind speed in the conduits of the study at the surface and 850 pHa pressure levels. (a) Profile for the mean wind speed in the first conduit from $14^{\text {th }}$ to $23^{\text {rd }}$ May 2020. (b) Profile for the mean wind speed in the second conduit from $20^{\text {th }}$ to $30^{\text {th }}$ May 2020. Note the wind speed at $850 \mathrm{pHa}$ pressure level is nearly double of the wind speed at surface level, particularly after basking session (approximately at $0800 \mathrm{Hrs}$.) for all the days where the swarms has transited using the conduits.

$$
W S_{850 \_ \text {conduit }} \geq 2 * W S_{\text {surf_conduit }}
$$

where $W S_{850}$ and $W S_{\text {surf }}$ are wind speeds at $850 \mathrm{hPa}$ level and surface levels respectively.

\section{Discussion}

Figure 6(a) shows the wind jets at $850 \mathrm{hPa}$ pressure level originated due to Amphan cyclone as on $19^{\text {th }}$ May 2020 and Figure 6(b) shows the situation of wind jets at $850 \mathrm{hPa}$ during the cyclone decay process post landfall $\left(24^{\text {th }}\right.$ May 2020), both in which clearly demonstrates that the cyclogenesis of Amphan has integrated the wind jets originated from the westerlies of the Thar desert region in its anticlockwise spin structure.

This sort of episodic phenomenon is quite rare as the westerly disturbances are independent to the synoptic features of cyclones originating in the basin of the Bay of Bengal. However, by virtue of this phenomenon the Southeastern winds originated from the westerlies of the scheduled Thar Desert region, maintained the same intensity upto the south-central parts of India throughout the living period of Amphan. Incidentally, numerous swarms that were oscillating in 
(a)
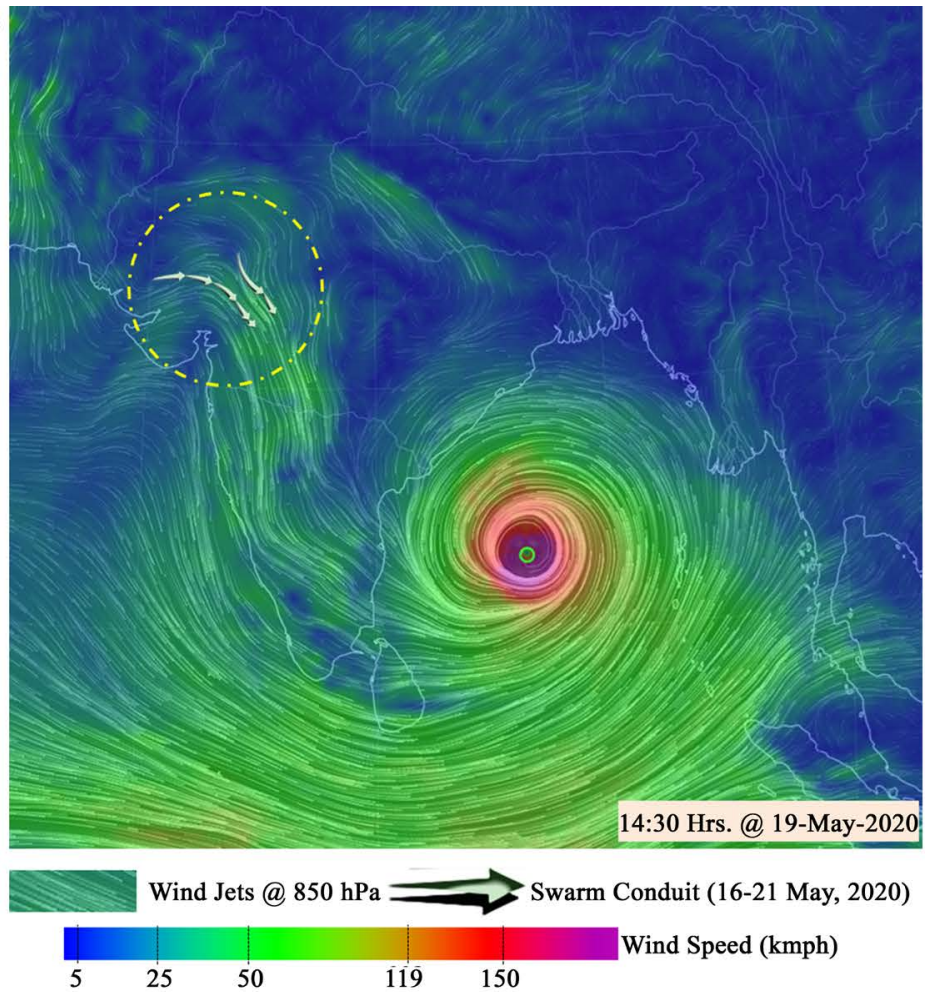

(b)

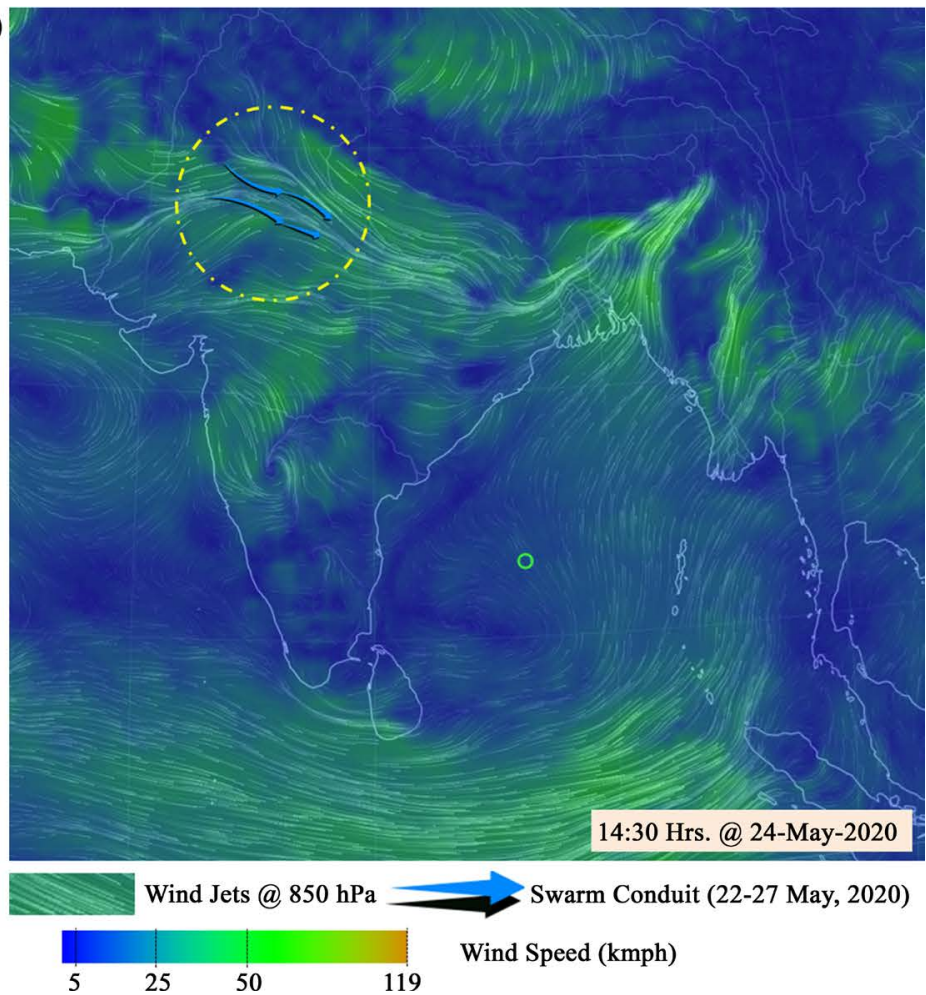

Figure 6. Wind jets at $850 \mathrm{pHa}$ during (a) living period of Amphan cyclone and (b) post Amphan cyclone. Note the integration of westerly wind jets (earmarked with yellow circle in a) originated from the Thar Desert region into the anticlockwise spin structure during the living period of Amphan cyclone. During the decay process of the cyclone the westerlies have continued in the energy balancing process towards easterlies. (Images adopted from the community maps of earth.nullschool.net). 
winds originated from the westerlies of the scheduled Thar Desert region, maintained the same intensity up to the south-central parts of India throughout the Thar Desert region got the trigger to migrate to the south-central parts of the country as the wind parameters favored in the conduit. Also, the phenomenon brought more swarms into the Indian territory of the Thar Desert region by $21^{\text {st }}$ May 2020 and these swarms further participated to migrate towards the Indo-Gangetic plain through the second conduit.

As illustrated in Table 3, a set of favorable conditions have aided in this sudden swarm migrations through these conduits. Factors like open sky conditions (cloud-free) and the ample air temperature immediately after sunrise have facilitated excellent basking environment to the locust. The relation between locust's body and air temperatures were discussed earlier and termed as a reflex provoking parameter for successful take-off (Kennedy, 1951; Gunn et al., 1948; Weis-Fogh, 1956). High availability of fresh vegetation in these conduits when compared to that of Thar desert has stimulated preferred feeding and roosting avenue to the locust. Food preferences of locust have explored earlier by the researchers and concluded that Locust prefers fresh vegetation over matured leaves (Waldner et al., 2015; Renier et al., 2015). The alongside Indo-Pak border regions and the Thar desert region provide necessary ecological conditions for oscillation, but for migration there needs external triggering factors (Uvarov, 1934; Ramchandra Rao, 1942). Wind parameters in the conduits during various phases of Amphan cyclone have acted as external triggers. Swarm migration has taken downwind displacement with the mean surface wind speed of less than 6 metres per second. As the wind directions in the first and second conduits are Southeastern and Eastern direction in which both are sun facing, and this factor too helped the swarms during the take-off session in the morning. The flying height preference of the swarms is nearly at lower troposphere, which is approximately $1500 \mathrm{~m}$ from the ground level (Rosenberg \& Burt, 1999; Cressman \& Stefanski, 2016). Observations from Equation (1) and Figure 5 emphasizes that wind speed which is double at $850 \mathrm{hPa}$ level with respect to that of surface wind speed after the take-off has acted as a catalyst in achieving this airborne displacement of swarms.

From the anecdotal records it was understood that swarms got scattered after reaching surroundings of Ujjain (in Madhya Pradesh state) which is the end point of first conduit. Similarly, swarms displaced unsystematically further to the interiors of Indo-Gangetic plain once they crossed the surroundings of Jhansi (situated in Uttar Pradesh state and border of Madhya Pradesh state) which is the end point of the second conduit (DownToEarth, 2020). The reason for this unsystematic scattering and displacement of swarms may be attributed to the varying ecological and weather settings at the local landscapes. However, swarms that migrated using the second conduit have reached the foothills of the Himalayas near Nepal after month-long oscillations in the Indo-Gangetic plane (DownToEarth, 2020). The concerned min- 
istries have released press information regarding affected areas in India due to locust (PIB, 2020).

\section{Conclusion}

In this article we presented the results after investigating the reasons for the swarm migration that happened from the scheduled Thar desert region to other parts of the country during the living and the decay period of the Amphan cyclone originated in the Bay of Bengal basin in the month of May 2020. The wind jets passing above the Thar desert region have integrated with the cyclogenesis of Amphan which led to the formation of conduits with favorable ecological conditions that acted as an external trigger for the migrations. These favorable conditions include the open sky setup for successful basking, air temperature which increased the thoracic temperature, and fresh vegetation availability with landscape suitable for night-time roosting. Moreover, the wind settings in the conduits have enabled the swarms to migrate through the downwind facing the morning sunrays for an easy and successful take-off. The results from this research are twofold; one is the identification of the concept of conduits for successful swarm migrations and the other is to recognize the unique condition where the wind speed at $850 \mathrm{hPa}$ level is mostly double than the surface wind speed during the take-off period.

The scope of future work can include effective integration of geospatial data and techniques to study all life cycle events of desert locust ranging from eggdevelopment stage, hopper and the winged adult.

\section{Acknowledgements}

We thank Director, National Remote Sensing Centre for facilitating the institutional support and for providing basic infrastructure for this investigation. We thank officials of Locust Warning Organization, ISRO Head Quarters, and scientific staff of RRSC-West, Jodhpur for providing constructive ideas related to this research. We are grateful to M.V Ramana, NRSC for providing insights related to the cyclogenesis and westerlies.

\section{Conflicts of Interest}

The authors declare no conflicts of interest regarding the publication of this paper.

\section{References}

Anstey, M. L., Rogers, S. M., Ott, S. R., Burrows, M., \& Simpson, S. J. (2009). Serotonin Mediates Behavioral Gregarization Underlying Swarm Formation in Desert Locusts. Science, 323, 627-630. https://doi.org/10.1126/science.1165939

Cabej, N. (2019). Epigenetic Principles of Evolution. Cambridge, MA: Academic Press. https://doi.org/10.1016/B978-0-12-814067-3.00003-X

Cressman, K. (1997). SWARMS: A Geographic Information System for Desert Locust Forecasting. In New Strategies in Locust Control (pp. 27-35). Basel: Birkhäuser. https://doi.org/10.1007/978-3-0348-9202-5 4 
Cressman, K. (2013). Climate Change and Locusts in the WANA Region. In Climate Change and Food Security in West Asia and North Africa (pp. 131-143). Dordrecht: Springer. https://doi.org/10.1007/978-94-007-6751-5 7

Cressman, K., \& Stefanski, R. (2016). Weather and Desert Locusts. Rome: FAO, UN.

Deb, S., Sankhala, D. K., Kumar, P., \& Kishtawal, C. M. (2020). Retrieval and Applications of Atmospheric Motion Vectors Derived from Indian Geostationary Satellites INSAT3D/INSAT-3DR. Theoretical and Applied Climatology, 140, 751-765. https://doi.org/10.1007/s00704-020-03120-8

DownToEarth (2020). Is India Headed towards a Locust Plague. https://www.downtoearth.org.in/news/wildlife-biodiversity/is-india-headed-towards-alocust-plague-72119

Gomez, D., Salvador, P., Sanz, J., Casanova, C., Taratiel, D., \& Casanova, J. L. (2018). Machine Learning Approach to Locate Desert Locust Breeding Areas Based on ESA CCI Soil Moisture. Journal of Applied Remote Sensing, 12, Article ID: 036011. https://doi.org/10.1117/1.JRS.12.036011

Gunn, D. L., Perry, F. C., Seymour, W. G., Telford, T. M., Wright, E. N., \& Yeo, D. (1948). Behaviour of the Desert Locust in Kenya in Relation to Aircraft Spraying. Anti-Locust Bulletin, London, 3, 70 p.

Hersbach, H. et al. (2020). The ERA5 Global Reanalysis. Quarterly Journal of the Royal Meteorological Society, 146, 1999-2049. https://doi.org/10.1002/qj.3803

IMD Indian Metrological Department (2020). Super Cyclonic Storm “Amphan” over the Southeast Bay of Bengal (16th-21st May 2020): Summary.

https://internal.imd.gov.in/press release/20200614 pr 840.pdf

Kennedy, J. S. (1951). The Migration of the Desert Locust (Schistocerca gregaria Forsk.) I. The Behaviour of Swarms. II. A Theory of Long-Range Migrations. Philosophical Transactions of the Royal Society of London. Series B, Biological Sciences, 235, 163-290. https://doi.org/10.1098/rstb.1951.0003

Locust Bulletin (2020). General Situation during April 2020 \& Forecast until Mid-June 2020. FAO-UN Desert Locust Bulletin No. 499. http://www.fao.org/ag/locusts/common/ecg/562/en/DL499e.pdf

Locust Hub (2020). An Initiative of the Food and Agriculture Organization of the United Nations. https://locust-hub-hqfao.hub.arcgis.com

Locust Watch (2020). Locust Watch: Desert Locust_Food and Agriculture Organization of the United Nations. http://www.fao.org/ag/locusts/en/info/info/index.html

Lorenz, M. W. (2009). Migration and Trans-Atlantic Flight of Locusts. Quaternary International, 196, 4-12. https://doi.org/10.1016/j.quaint.2007.09.038

LWO (2020). Locust Warning Organisation-India: Locust Control \& Research. http://ppqs.gov.in/divisions/locust-control-research

Makra, L., Bodnár, K., et al. (2017). The First Record of Subtropical Insects (Thysanoptera) in Central Europe: Long-Distance Transport of Airborne Thrips, Applying Three-Dimensional Backward Trajectories. Agricultural and Forest Entomology, 20, 301-326. https://doi.org/10.1111/afe.12260

Outlook (2020). Locust Attack in 15 Madhya Pradesh Districts. https://www.outlookindia.com/newsscroll/locust-attack-in-15-madhya-pradesh-distric $\underline{\mathrm{ts} / 1841233}$

Pedgley, D. (1980). Desert Locust Forecasting Manual (Volume 2 of 2). London: Centre for Overseas Pest Research.

PIB (2020). Damage to Crops Due to Locust Attack. 
https://pib.gov.in/PressReleaseIframePage.aspx?PRID=1656134

Ramchandra Rao, R. B. Y. (1942). Some Results of Studies on the Desert Locust (Schistocerca gregaria, Forsk.) in India. Bulletin of Entomological Research, 33, 241-265. https://doi.org/10.1017/S0007485300026572

Ramon, J., Lledó, L., Torralba, V., Soret, A., \& Doblas-Reyes, F. J. (2019). What Global Reanalysis Best Represents Near-Surface Winds? Quarterly Journal of the Royal Meteorological Society, 145, 3236-3251. https://doi.org/10.1002/qj.3616

Renier, C., Waldner, F., Jacques, D., Babah Ebbe, M., Cressman, K., \& Defourny, P. (2015). A Dynamic Vegetation Senescence Indicator for Near-Real-Time Desert Locust Habitat Monitoring with MODIS. Remote Sensing, 7, 7545-7570. https://doi.org/10.3390/rs70607545

Richardson, C. H., \& Nemeth, D. J. (1991). Hurricane-Borne African Locusts (Schistocerca gregaria) on the Windward Islands. GeoJournal, 23, 349-357.

https://doi.org/10.1007/BF00193608

Rosenberg, J., \& Burt, P. J. A. (1999). Windborne Displacements of Desert Locusts from Africa to the Caribbean and South America. Aerobiologia, 15, 167-175. https://doi.org/10.1023/A:1007529617032

Simpson, S. J., \& Sword, G. A. (2009). Phase Polyphenism in Locusts: Mechanisms, Population, Consequences, Adaptive Significance and Evolution. In D. W. Whitman, \& T. N. Ananthakrishnan (Eds.), Phenotypic Plasticity of Insects: Mechanisms and Consequences (147-189). Plymouth: Science Publishers, Inc.

Song, H. (2004). Revision of the Alutacea Group of Genus Schistocerca (Orthoptera: Acrididae: Cyrtacanthacridinae). Annals of the Entomological Society of America, 97, 420-436. https://doi.org/10.1603/0013-8746(2004)097[0420:ROTAGO]2.0.CO;2

Steedman, A. (1988). Locust Handbook. London: Overseas Development Agency, National Resources Institute.

Symmons, P. M., \& Cressman, K. (2001). Desert Locust Guidelines: Biology and Behaviour. Rome: FAO.

The Hindu (2020). Ten U.P. Districts on Alert after Locust Swarms Attacks Crops in Neighbouring Rajsthan, M.P.

https://www.theweek.in/news/india/2020/05/26/ten-up-districts-on-alert-after-locust-s warms-attack-crops-in-rajasthan-mp.html

Topaz, C. M., D’Orsogna, M. R., Edelstein-Keshet, L., et al. (2012). Locust Dynamics: Behavioral Phase Change and Swarming. PLoS Computational Biology, 8, e1002642. https://doi.org/10.1371/journal.pcbi.1002642

Uvarov, B. P. (1934). The Locust Outbreak in Africa and Western Asian in 1933. Publication No. 63-80-3, London: His Majesty's Stationery Office.

Waldner, F., Ebbe, M., Cressman, K., \& Defourny, P. (2015). Operational Monitoring of the Desert Locust Habitat with Earth Observation: An Assessment. ISPRS International Journal of Geo-Information, 4, 2379-2400. https://doi.org/10.3390/ijgi4042379

Wang, Y. P., Wu, M. F., Lin, P. J., Wang, Y., Chen, A. D., Jiang, Y. Y., \& Hu, G. (2020). Plagues of Desert Locusts: Very Low Invasion Risk to China. Insects, 11, 628. https://doi.org/10.3390/insects11090628

Weis-Fogh, T. (1956). Biology and Physics of Locust Flight II. Flight Performance of the Desert Locust (Schistocerca gregaria). Philosophical Transactions of the Royal Society of London. Series B, Biological Sciences, 239, 459-510.

https://doi.org/10.1098/rstb.1956.0008 
Wilps, H. (1997). Ecology of Schistocerca gregaria (Forskål): Observations in West Africa from 1990 to 1994. In New Strategies in Locust Control (pp. 9-17). Basel: Birkhäuser. https://doi.org/10.1007/978-3-0348-9202-5 2

Yang, H., Yang, X., Heskel, M., Sun, S., \& Tang, J. (2017). Seasonal Variations of Leaf and Canopy Properties Tracked by Ground-Based NDVI Imagery in a Temperate Forest. Scientific Reports, 7, Article No. 1267. https://doi.org/10.1038/s41598-017-01260-y 